\title{
APPLICATIONS OF FACT IN THE ACADEMIC CONTEXT TO IMPROVE THE HEALTH OF HIGH SCHOOL STUDENTS
}

\author{
Juan José Macías Morón ${ }^{1}$ and Luis Valero-Aguayo² \\ ${ }^{1}$ Saint Anthony Catholic University of Murcia; ${ }^{2}$ University of Malaga (Spain)
}

\begin{abstract}
There is growing evidence showing the efficacy of contextual or thirdgeneration therapies in various contexts and clinical conditions. In large groups of first- and second-year high school students $(n=112)$, the present study compares the efficacy of applying a program based on Acceptance and Commitment Therapy (ACT) versus a combined program using strategies from Functional-Analytical Psychotherapy (FAP), resulting in a so-called FACT approach. The purpose of this intervention was to extract the most relevant processes underpinning clinical changes to design training programs based on contextual behavioral science to improve students' health. The results indicated that both interventions produced statistically significant improvement in the health of the students. The program combined with FACT was superior in the self-concept variable. The implications of both brief programs to improve students' health in short periods are discussed on the basis of a behavioral methodology adapted to the academic context.

KEY WORDS: brief therapy, contextual therapies, FACT, school health.
\end{abstract}

\section{Resumen}

Las terapias contextuales o de tercera generación cada vez acumulan más evidencia sobre su eficacia en diferentes contextos y condiciones clínicas. Este estudio compara en estudiantes de primero y segundo de bachillerato $(n=112)$, la eficacia de un programa basado en la terapia de aceptación y compromiso (ACT) frente a un programa combinado añadiendo estrategias de la psicoterapia analítica funcional (FAP) y resultando en una aproximación denominada terapia funcional de aceptación y compromiso (FACT). El propósito de esta intervención consistió en extraer los procesos más relevantes para el cambio, con el objetivo de diseñar programas de formación basados en la ciencia conductual contextual para mejorar la salud de los estudiantes. Los resultados indicaron que ambas intervenciones produjeron cambios estadísticamente significativos mejorando la salud de los estudiantes. El programa combinado con FACT fue superior en la variable autoconcepto. Se discuten las implicaciones y diferencias de ambos programas breves para mejorar la salud de los estudiantes en breves periodos de tiempo, desde una metodología conductual adaptada al contexto académico.

PALABRAS CLAVE: programa breve, terapias contextuales, FACT, salud escolar.

Correspondence: Juan José Macías Morón, Professor, Faculty of Health Sciences, Psychology Degree, s/n, 30107 Murcia (Spain). E-mail: jjmacias@ucam.edu 


\section{Introduction}

In recent decades, various epidemiological studies have documented high levels of psychological distress among students (Duffy, Twenge, \& Joiner, 2019; Takashi et al., 2020). Although students experience high levels of psychological distress, only between 11.7-18.45\% decide to seek help (Blanco et al., 2008). The consequences of psychological distress often interfere with various aspects of students' lives, such as academic performance, daily activities, physical and emotional health, and quality of life (Andrews and Wilding, 2004). And while adolescence can be turbulent, it can also mark the emergence of strategies that promote development and change the course of adult life. Indeed, interventions during adolescence could be an indicator for later success (Swain, Hancock, Dixon, \& Bowman, 2015). The aim is to prevent future problems before university, where most of the difficulties of adult life begin (Megivern, Pellerito, \& Mowbray, 2003).

As a transdiagnostic model, different interventions based on functional contextualism have been postulated, including the philosophy of Skinnerian experimental behaviour analysis adapted to the clinical environment. The two most representative therapies from this framework are acceptance and commitment therapy (ACT; Hayes, Strosahl, \& Wilson, 1999) and functional analytic psychotherapy (FAP; Kohlenberg a \& Tsai, 2021), which have yielded consistent results across different clinical conditions (A -Tjak et al., 2015; Hayes, Luoma, Bond, Masuda, \& Lillis, 2006; Kanter et al., 2017). Both approaches use an analytical and contextual behavioral framework to address complex clinical problems, whose clinical vehicle is the therapeutic relationship and acceptance. Likewise, both are rooted in the principles of behavior such as negative and positive reinforcement, shaping, extinction, escape, and avoidance, applying them to private events and interpersonal interactions under functional analysis. From a philosophical standpoint, the theoretical roots of both approaches do not differ in the sense that they are analytical and based on behavioral therapy. Their joint adaptation shares their philosophy of science. Since their inception, both psychotherapies have grown, and evidence has been provided for each of them. Acceptance and commitment therapy is based more on the derived and framed language processes through verbal behavior, developed from the theory of relational frames (Hayes et al., 2001), while functional analytic psychotherapy is based on contingencies, which occur in-session, to produce changes in situ. Likewise, it generates the appropriate contingencies, using shaping, the therapeutic relationship, and functional generalization to modify the individual's behavior inside and outside the session. Functional analytic psychotherapy can be summarized as a deeper therapy that seeks to produce radical changes in people, particularly when treating complex and interpersonal problems. Acceptance and commitment therapy (ACT) may be more applicable as its processes are less invasive and more attractive for students. Therefore, the previous learning of a basic repertoire of acceptance before tackling complex problems has shown its usefulness for subsequently generating a context for creating a therapeutic relationship (Callaghan et al., 2004). This therapy has been successfully applied in the educational environment (Danitz, Suvak, \& Orsillo, 2016; García-Pérez \& Valdivia-Salas, 2018; Gillard, Flaxman, \& Hooper, 2018; Lillis \& Hayes, 2007). The 
combination of both approaches has also shown effectiveness in the academic environment to improve student health and academic achievement (Cativelli, Musetti, \& Perini, 2014; Macías \& Valero, 2021a,b; Páez-Blarrina \& Luciano, 2012).

It has already been shown in the literature that both approaches applied together can act synergistically. In particular, they were applied jointly in the beginning because they shared contextual origins, and combining them was inevitable (Callaghan et al., 2004; Kohlenberg, Hayes, \& Tsai, 1993; Tsai et al., 2009). The benefits offered by both approaches inevitably lead to combining them. It is thus important to determine the scope of their integration and observe the possible differential effects of the short program with FACT (functional acceptance and commitment therapy) where the most important processes of ACT and FAP converge, compared to applying a program that uses only ACT. Thus, this study could provide the starting point for collecting information on the processes that may be most important in improving students' health. Likewise, it can be the gateway to using complex procedures based on behavioral and clinical psychotherapies that are adapted and converted to the students' language in a minimally invasive and engaging way. In sum, the purpose is to offer evidence-based interventions promoting adherence with simple but profound methodology and terminology.

\section{Method}

\section{Participants}

This study was carried out with groups of first and second-year high school students (between 16 and 19 years old; mean age $=17.18$ ). A total of 112 students (47 males and 65 females) completed all the evaluation questionnaires. Subsequently, they were assigned to two groups according to their already established membership of the first year of high school $(n=71)$ and second year $(n=$ 41). The first group had a mean age of 16.67 years and the second a mean age of 17.70 years. Thus, there were 38 girls and 33 boys in the first year of high school, while in the second year, there were 27 girls and 14 boys. All the students belonged to the same institute, and the sessions were held in the classroom of each course. The inclusion criteria for the study were that the participants performed at least two of the three sessions and that their participation was voluntary since anyone could benefit from an effective intervention.

\section{Instruments}

a) General Health Questionnaire-12 (GHQ-12; Goldberg, 1992), Spanish version developed by Sánchez-López and Dresch (2008). This scale is a 12-item selfreport questionnaire that measures psychological well-being. Items are rated using a four-point scale from 0 ("better than usual") to 4 ("much less than usual". Scores above 12 on the items indicate higher levels of psychological distress. In the Spanish adaptation the Cronbach's alpha coefficient was 0.76, and in this study was 0.70 . 
b) Satisfaction with Life Scale (SWLS; Diener, Emmons, Larson, \& Griffin, 1985), Spanish version developed by Atienza, Pons, Balaguer, \& García-Merita (2000). This scale is a 5-item questionnaire designed to measure life satisfaction. Participants indicate how much they agree or disagree with these items using a 7-point scale that ranges from 1 ("strongly disagree") to 7 ("strongly agree"). Higher scores on this questionnaire show greater satisfaction with life. Cronbach's alpha coefficient for this scale ranges from 0.79 to 0.89 ; in this study it was 0.83 .

c) Acceptance and Action Questionnaire // (AAQ-II; Bond et al., 2011), Spanish version developed by Ruiz, Langer, Luciano, Cangas, \& Beltrán (2013). This scale is a 7-item Likert-type self-report questionnaire created to measure psychological flexibility. This scale assesses experiential avoidance and psychological acceptance, which are key aspects of ACT. It has seven items rated from 1 ("never") to 7 ("always"). Higher scores indicate lower levels of psychological flexibility. Cronbach's alpha coefficient ranged from 0.79 to 0.84 ; and in this this study it was 0.88 .

d) Mindful, Attention and Awareness Scale (MAAS; Brown \& Ryan, 2003), Spanish version developed by Soler et al. (2012). This questionnaire consists of 15 items scored according to a Likert scale ranging from 1 ("almost always") to 6 ("rarely"). It measures the degree of mindfulness in daily life and can be applied without the participants having previous experience with mindfulness training. The score is obtained from the arithmetic mean of the total of the items. Higher scores indicate a greater state of mindfulness. Cronbach's alpha coefficient for the original scale ranges from 0.80 to 0.87 ; in this study it was 0.89 .

e) Self-concept Scale Form 5 (AF5; García \& Musitu, 1999). This questionnaire consists of 30 items and assesses five dimensions of self-esteem ( 6 items of each dimension): academic, social, emotional, family, and physical. All items have a response scale of 1-99. The higher the score obtained on each dimension, the greater the self-concept in that area. Previous research has found Cronbach's alpha values of .89 (academic), .73 (social), .73 (emotional), .80 (family), and .78 (physical). En este estudio, fue de 0,78 (académica), 0,70 (social), 0,80 (emocional), 0,85 (familiar) y 0,75 (física).

\section{Procedure}

A between-group design with repeated measures was used, with a waiting list control group. Participants were assigned to the group according to their academic year. The first-year high school students completed the first phase as a control group on the waiting list. After the evaluation and after a month of waiting, they were evaluated again. From there, the intervention with the FACT program began. The second-year high school students directly received the brief intervention with ACT and were evaluated again at the end. Thus, both groups received three sessions with one or the other intervention, depending on the group to which they belonged. The scheme in Figure 1 presents the experimental design and the number of participants in each group. 
Figure 1

Explanatory diagram of assignment to the ACT and FACT group

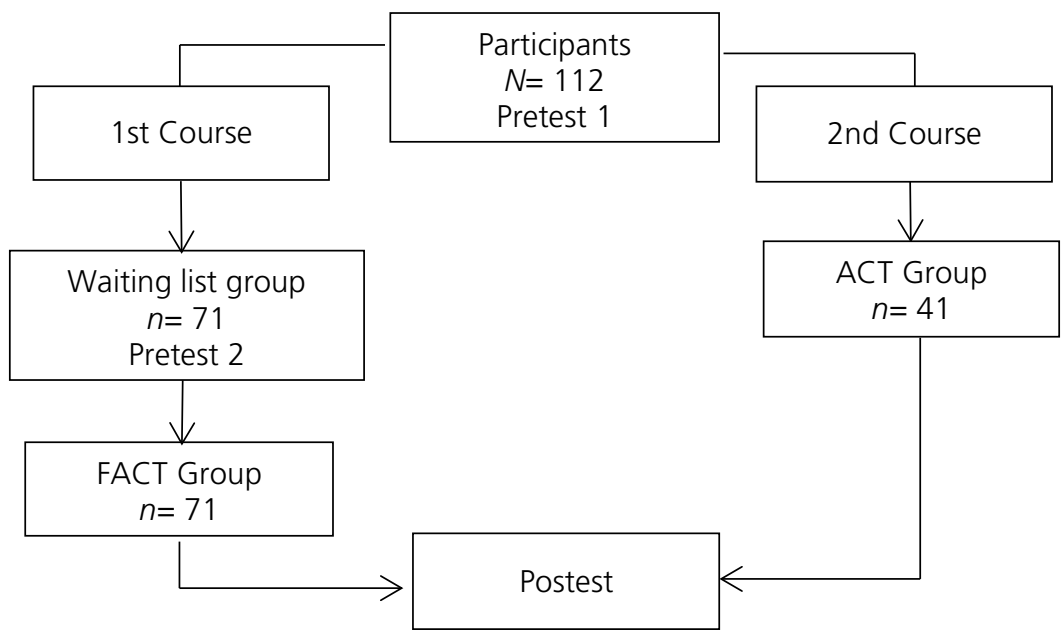

Note: $\mathrm{FACT}=$ functional acceptance and commitment therapy; $\mathrm{ACT}=$ acceptance and commitment therapy.

The students began participating in this study by meeting with the institute's board of directors to promote health in the academic environment, demanded by the center's head of studies. This study was carried out in a secondary school in Marbella (Malaga), in the same classroom, during a free hour in their school timetables. Each group received an intervention consisting of three group sessions: one group with ACT and another with FACT. The ethics committee approved this study with CEUMA registration number: 47-2018-H. Along with this, all participants filled the informed consent about the purpose of the study, the confidentiality, and anonymous data processing.

Attendees had to complete at least two of the three sessions to be included in the study. The first two sessions took place in consecutive weeks, and the final session took place after two weeks. This period was used to practice the skills learned in the first two sessions. The ACT group received the intervention after completing the questionnaires, while the FACT group remained on the waiting list for one month as a control group. After that month, they took another assessment measure to observe any differences and immediately began the intervention. Each group session lasted 60 minutes in the students' usual classroom. The FACT group was assembled in a special classroom to accommodate the 71 students, and the post-test measurements were completed after the last session.

None of the FAP components were used in the ACT group to be as strict as possible with the program. Appendices 1 and 2 show the different elements that were incorporated in both ACT and FACT. The program combined with FACT also included therapeutic rules, shaping, and relational interaction used by FAP. 
Interventions were delivered using an adaptation of the " $2+1$ " format (Barkham \& Shapiro, 1990), which has proven useful over time under different conditions. The essence of the intervention was inspired by the previous works of Strosahl, Robinson, and Gustavsson (2012), and Glover et al. (2016); interactions and rules of FAP (Tsai et al., 2009); and ACT strategies adapted to the work context (Flaxman, Bond, \& Livheim, 2013) as well as the methodology included in Macías and Valero (2021a). Some procedures such as "mindfulness" were included from an analytical-functional perspective, along with extinction/differential reinforcement, contact with the present, and dismantling of the aversive functions of language, all adapted to the students' verbal context. It was more attractive for them to use terminology linked to mindfulness with examples based on shaping, for example, through athletes, singers, and actresses who practice it. However, more complex processes such as modeling, shaping, or perspective-taking were worked on in the previous sessions with the students. The terminology was altered to increase the adherence and participation of the students, with examples, images, and videos.

In both interventions, the philosophy consisted of treating each session as if it were the last meeting together, inducing radical changes and promoting functional generalization in the case of the FACT group (see Appendix). The central processes used were the results of their own experience on avoidance (creative hopelessness) and acceptance of private experiences (Wang, Hagger, \& Chatzisarantis, 2020). The aim was to promote mindfulness, awareness, and commitment to a meaningful connection with the presence of annoying private events.

In the initial session, the benefits of the program and the applications to daily life were presented. Then, control as a problem and experiential avoidance were described, along with a group descriptive functional analysis (Table 1). This also included the most common private events and the ways of relating to these events, clarification of values and commitment, creative hopelessness, and, finally, the Self as a context (acting with barriers), all of them adapted to the youth status of the students.

The second session focused on a summary of the previous session, which included defusion exercises, promoting attention and awareness, the willingness to deal with unpleasant private events (thoughts, sensations, feelings, and emotions), and perspective-taking through participation in the hierarchical framing along with the perspective of "Self" (Törneke, Luciano, Barnes-Holmes, \& Bond (2015). FAP strategies were integrated into all exercises, except in the group that received the ACT intervention. Following FAP principles, an intense and genuine therapeutic relationship was promoted with all students, allowing personal self-disclosures to serve as a model to shape clinically relevant behaviors. As a result, clinically relevant behaviours type 1 was elicited in situ, and clinically relevant behaviours type 2 was enhanced, while type 3 and functional generalization were promoted (MuñozMartínez \& Follete, 2019).

The final session aimed to promote the commitment to live based on values (e.g., studying for a career, having better social relationships, and improving the relationship with the partner and family). In addition, relapse prevention and acceptance of discomfort were worked on. All group sessions included tasks to 
practice at home related to the content of each session, along with exercises and metaphors to produce functional generalization in the students' daily lives.

Table 1

Functional analysis about general problems of the groups

\begin{tabular}{|c|c|c|}
\hline Internal Events & How do I relate? & Consequences \\
\hline Fear & Sleep & Short term: \\
"I am going to fail." & Drink Alcohol & Pills \\
"I am not good enough" & Stay at home & Pr+ Following verbal rules ("I \\
"I can't do it." & have to remove this \\
"I am idiot." & Play videogames \\
"The others are better than & $\begin{array}{c}\text { Use the mobile phone } \\
\text { me." }\end{array}$ & Isolate \\
Shame & Don't study & Nr- Avoidance \\
Distress & Procrastinate \\
Anxiety & Lie \\
Laziness & Don't speak \\
Apathy & Watch tv series & Long term: \\
Guilt & Other avoidance \\
& behaviors & It does not work \\
& Boomerang effect \\
\hline
\end{tabular}

Note: $\mathrm{Pr}+=$ positive reinforcement; $\mathrm{Nr}$ - = negative reinforcement.

\section{Data analysis}

To analyze the effects of the intervention with FACT and ACT, an ANOVA ( $2 x$ 2) was used with a between-group design and pre-post repeated measures to determine the differences in the variables: general health, life satisfaction, psychological flexibility, mindfulness, and self-concept (through the questionnaires GHQ-12, AAQ -2, SWLS, MAAS, and AF5). In addition, the FACT group was taken as a control group on the waiting list (pre2) for the same group, and a Student's ttest was performed to observe differences between pre 1 and pre2. Finally, the effect sizes of the pre-post differences in the ACT group were also calculated with Cohen's $d$ to observe the magnitude of the changes in each group. According to Cohen (1992), rates of 0.10 indicate small effect sizes, 0.30 indicate medium effect, and 0.50 indicate large effect.

\section{Results}

The means and standard deviations of the pre1, pre2, and post-treatment data of the ACT and FACT group in the variables studied are displayed in Table 2.

In the FACT intervention group, the Student's $t$-test revealed no statistically significant differences in any variable when comparing pre1 and pre2 (waiting list group). Therefore, the students did not improve over time, and the scores of the dependent variables remained the same. This month of waiting served as a reference or control group to observe if changes occurred in the subsequent measurement due to the intervention. 
Table 2

Means and standard deviation of the three groups in the pre1, pre2, and post-treatment

\begin{tabular}{|c|c|c|c|c|c|}
\multirow{2}{*}{$\begin{array}{c}\text { Variables } \\
\text { (instruments) }\end{array}$} & \multicolumn{2}{c|}{$\begin{array}{c}\text { Waiting-list } \\
\text { Group }\end{array}$} & \multicolumn{2}{c|}{$\begin{array}{c}\text { FACT } \\
\text { Group }\end{array}$} & \multicolumn{2}{c|}{$\begin{array}{c}\text { ACT } \\
\text { Group }\end{array}$} \\
\cline { 2 - 6 } & Pre1 & Pre2 & Pos & Pre1 & Pos \\
\hline \multirow{2}{*}{ Psychological well-being (GHQ-12) } & 13.98 & 12.23 & 8.70 & 15.31 & 7.05 \\
& $(7.01)$ & $(6.73)$ & $(3.75)$ & $(6.63)$ & $(4.36)$ \\
\hline \multirow{2}{*}{ Psychological flexibility (AAQ-2) } & 22.57 & 20.31 & 19.85 & 22.60 & 18.05 \\
& $(9.66)$ & $(8.87)$ & $(6.90)$ & $(9.14)$ & $(7.44)$ \\
\hline \multirow{2}{*}{ Life satisfaction (SWLS) } & 21.22 & 21.89 & 23.65 & 24.31 & 28.18 \\
& $(6.39)$ & $(6.68)$ & $(5.40)$ & $(5.68)$ & $(5.45)$ \\
\hline \multirow{2}{*}{ Mindfulness (MAAS) } & 57.85 & 59.36 & 63.24 & 61.82 & 73.26 \\
& $(25.08)$ & $(23.80)$ & $(15.98)$ & $(19.89)$ & $(7.11)$ \\
\hline Self-concept (AF5) & & & & & \\
\hline \multirow{2}{*}{ Academic } & 5.33 & 5.61 & 6.58 & 6.19 & 7.27 \\
& $(2.33)$ & $(2.57)$ & $(1.09)$ & $(3.27)$ & $(1.68)$ \\
\hline \multirow{2}{*}{ Social } & 5.95 & 6.58 & 6.98 & 6.75 & 7.14 \\
& $(2.40)$ & $(1.91)$ & $(1.69)$ & $(2.08)$ & $(1.79)$ \\
\hline \multirow{2}{*}{ Emotional } & 5.98 & 5.97 & 6.95 & 5.43 & 6.01 \\
& $(2.19)$ & $(2.39)$ & $(1.86)$ & $(2.08)$ & $(2.65)$ \\
\hline \multirow{2}{*}{ Family } & 7.31 & 7.51 & 7.71 & 7.79 & 7.91 \\
& $(2.48)$ & $(3.19)$ & $(2.20)$ & $(1.85)$ & $(2.14)$ \\
\hline \multirow{2}{*}{ Physical } & 5.53 & 5.67 & 6.04 & 5.58 & 5.82 \\
& $(2.82)$ & $(2.91)$ & $(2.34)$ & $(3.03)$ & $(2.49)$ \\
\hline
\end{tabular}

Note: $\mathrm{FACT}=$ functional acceptance and commitment therapy; $\mathrm{ACT}=$ acceptance and commitment therapy; GHQ-12= General Health Questionnaire; SWLS= Satisfaction with Life Scale; AAQ-II= Acceptance and Action Questionnaire; MAAS= Mindful Attention Awareness Scale; AF5= Self-Concept Form 5.

After the FACT intervention, the students showed a significant increase in scores compared with the control group on the waiting list, which indicates that FACT is more effective than no intervention (see Table 2), in the academic, social, and emotional variables measured. At the same time, the ACT intervention was also effective, with statistically significant improvements in all measurements (see Table 2). In other words, this group that received the ACT intervention, which was also brief, showed significant changes in the health variables, particularly in mindfulness and life satisfaction. However, no changes were observed in the AF5 questionnaire items related to academic, social, emotional, family, and physical self-concept.

The ANOVA conducted to compare ACT and FACT pre-post scores revealed differences between the two groups in mindfulness and life satisfaction (MAAS and SWLS) in favor of the ACT group. In contrast, the FACT group showed higher scores on the academic and emotional variables of the self-concept (AF5) as it can be seen in Table 3). Therefore, both interventions effectively improve students' health, although the effects differed from one group to the other for the variables of mindfulness and self-concept. 
Table 3

ANOVA test results for pre-post comparison of FACT and ACT groups

\begin{tabular}{|l|c|c|c|c|c|}
\hline \multicolumn{1}{|c|}{ Variables (instruments) } & SC & $F$ & $p$ & $\eta^{2}$ & Cohen's d \\
\hline Psychological well-being (GHQ-12) & 1.214 & 0.035 & .852 & 0.001 & 0.405 \\
\hline Psychological flexibility (AAQ-2) & 37.756 & 0.332 & .566 & 0.003 & 0.250 \\
\hline Life Satisfaction (SWLS) & 703.851 & 13.229 & .001 & 0.114 & 0.835 \\
\hline Mindfulness (MAAS) & 2532.991 & 5.094 & .026 & 0.045 & 0.810 \\
\hline Self-concept (AF5) & & & & & \\
\hline Academic & 31.171 & 5.091 & .026 & 0.044 & 0.487 \\
\hline Social & 11.668 & 1.873 & .174 & 0.017 & 0.091 \\
\hline Emotional & 28.915 & 4.865 & .029 & 0.042 & 0.410 \\
\hline Family & 5.878 & 0.794 & .375 & 0.007 & 0.090 \\
\hline Physical & 1106.018 & 0.037 & .848 & 0.037 & 0.091 \\
\hline
\end{tabular}

Note: $\mathrm{FACT}=$ functional acceptance and commitment therapy; $\mathrm{ACT}=$ acceptance and commitment therapy; GHQ-12= General Health Questionnaire; SWLS= Satisfaction with Life Scale; AAQ-II= Acceptance and Action Questionnaire; MAAS= Mindful Attention Awareness Scale; AF5= Self-Concept Form 5.

Regarding the effect size, the results showed that the FACT group obtained a medium effect size, but greater that the ACT group for the variables of self-concept (academic and emotional). Therefore, this effect size was significantly larger in the ACT group compared to FACT on the mindfulness and life satisfaction variables. While the pre-post effect size was medium for FACT in the case of psychological flexibility, life satisfaction, and academic and emotional self-concept. That is, in this group, participants benefit in these aspects with a combined FACT brief programme. However, larger effect sizes appeared in ACT for psychological well-being and flexibility, mindfulness, and life satisfaction. This would indicate a greater benefit in these specific aspects in the ACT-only group.

\section{Table 4}

Effect sizes (Cohen's $d$ ) for FACT and ACT groups in the pre-post measurements

\begin{tabular}{|l|c|c|}
\hline \multicolumn{1}{|c|}{ Variables (instruments) } & FACT & ACT \\
\hline Psychological well-being (GHQ-12) & 0.56 & 0.70 \\
\hline Psychological flexibility (AAQ-2) & 0.35 & 0.49 \\
\hline Mindfulness (MAAS) & 0.06 & 0.51 \\
\hline Life satisfaction (SWLS) & 0.41 & 0.60 \\
\hline Self-concept (AF5) & & \\
\hline Academic & 0.47 & 0.41 \\
\hline Social & 0.22 & 0.20 \\
\hline Emotional & 0.36 & 0.24 \\
\hline Family & 0.07 & 0.05 \\
\hline Physical & 0.14 & 0.08 \\
\hline
\end{tabular}

Note: $\mathrm{FACT}=$ functional acceptance and commitment therapy; $\mathrm{ACT}=$ acceptance and commitment therapy; GHQ-12= General Health Questionnaire; SWLS= Satisfaction with Life Scale; AAQ-II= Acceptance and Action Questionnaire; MAAS= Mindful Attention Awareness Scale; AF5= Self-Concept Form 5. 


\section{Discussion}

The objectives of this research were: 1) to extend the applications of FACT in the academic context to produce positive changes in the psychological well-being, satisfaction with life, self-concept, and mindfulness of students; 2) to determine which intervention (ACT or FACT) may be more useful for improving the variables analyzed; 3) to clarify any differences in the effects produced by the two interventions; 4) to determine the benefits of using one approach or another and verify if using the components in large groups for short periods based on a rigorous philosophy of science is effective with this student sample.

To examine the effectiveness of both interventions, students completed a battery of questionnaires and were assigned to either the FACT group or the ACT group. The FACT group remained on the waiting list for one month as a control group. Subsequently, they returned to complete the same battery of questionnaires to observe any changes that may have occurred during the waiting month. The results indicate that both intervention (ACT and FACT) is effective in improving psychological well-being and life satisfaction, which were the main goals of the intervention.

Both interventions have been found to be effective for the mentioned variables, and both modalities show some variation in the results, which may lead to different consideration and implications. In fact, it seems that the ACT group is superior in psychological flexibility, mindfulness, and life satisfaction. An effect that could be due precisely to the fact that this group focuses primarily on these concepts for mindfulness and values in life. While the FACT group also improves in life satisfaction and psychological flexibility but to a lesser extent and seems to be higher in academic and emotional self-concept. The scores obtained in these sections of self-concept are higher than the mean scores proposed by the classic authors of the instrument (García \& Musitu, 1999). Academic self-concept has been generally related to academic performance $(r x y=.60)$. In addition, it has been associated with quality of work performance, acceptance and esteems of peers, responsibility and leadership, quality of work performance and acceptance. Thus, we can assume that these dimensions are related to better psychosocial adjustment in the case of adolescents who are studying high school level (Kulakow, 2020). These data could suggest that the intervention with FACT is slightly superior to ACT in achieving those educational goals and adjustment to the academic context that would be necessary in an adolescent population.

Perhaps, the differences in mindfulness and psychological flexibility may be because FACT has not focused strictly on the six key processes of hexaflex from ACT (Stabbe et al., 2019; Hayes, 2019), and because it is a more complex intervention in terms of the mechanisms of change. On the contrary, the programme with ACT was more in line with the key processes proposed by hexaflex, so it is assumed that changes have occurred consistently with the postulates of ACT (Hayes, 2019).

On the other hand, Callaghan et al. (2004) described a series of indications to complement ACT and FAP, suggesting that ACT could be more appropriate at the beginning of the intervention because it is an interesting approach for people, after which it might be useful to establish the therapeutic relationship based on the direct 
contingencies of FAP while simultaneously applying ACT. At the beginning of the intervention, the purpose is to establish acceptance and mindfulness skills to encourage psychological flexibility and committed action. Once this goal has been achieved, more meaningful interpersonal relationships could be facilitated and created for participants both within and outside of therapy. Thus, perhaps, the improvements in self-concept may be due to the establishment of a genuine relationship from the beginning in the group that received the intervention, which served as a therapeutic context and vehicle to bond them with academic studies.

These data could provide the starting point for combining ACT with FAP synergistically in all contexts, as suggested by previous findings (Macías et al., 2019; Macías \& Valero, 2021a), bringing together the most effective processes. Consequently, it will be possible to train other professionals to apply these therapies in the academic context by offering a proposal rooted in behavioral psychology while also presented in a way that is attractive to students. Furthermore, the findings are consistent with other interventions based on third-generation therapies in academic contexts (Grégoire et al., 2018; Halliburton \& Cooper, 2018; Keogh et al., 2006; Swain et al., 2015) and with brief interventions aimed at improving health in other contexts based on the same philosophy (Glover et al., 2016; Strosahl et al., 2012).

Another important aspect to highlight is that ACT in its short format is so effective than its longer versions (Powers et al., 2009), providing information on its efficiency and cost savings compared with longer interventions. Likewise, the most solid aspect of this work is that both interventions (used together or separately) show better outcomes for all variables than the waiting list control group.

However, although the data found in this intervention provide a preliminary step towards further developing strategies based on brief ACT and FACT, this study has a series of limitations. First, the ACT group did not have a control group. However, the waiting list control group was used to compare the effectiveness of non-intervention, between the first and second evaluation, just before starting the FACT program. However, due to the institute's schedule with the planning of the classes, a different control group could not be used for each intervention, although it has already been shown by other investigations that ACT is superior to the control group (Hayes et al., 2006). Thus, for future research, it is recommended to introduce another control condition for the intervention. A further limitation is that participants of the ACT group ( $n=41)$ were in the second year of high school while those of the FACT group were in the first year $(n=71)$. This discrepancy raises questions about group differences (different teachers, ages, academic years, and circumstances), which are potentially confounding variables, making the comparison between both groups difficult. In addition, the experimental group included more participants because there were more students in that year.

While the FACT intervention yielded positive results in self-concept and ACT did not, the differences were not substantial. However, this implies that the superior results of FACT compared with ACT cannot be generalized, and further tests are needed to demonstrate its comparative efficacy, both in other educational centers and in other contexts.

Although these data are to be viewed with caution, this study may provide the starting point for a generation of evidence-based therapies and relevant processes 
that can be applied to produce therapeutic change, as shown by the FACT intervention. Furthermore, both approaches could be taught comprehensively due to their theoretical and practical richness, combining the most relevant processes to produce rapid and radical changes, adapting to today's society's changing needs, and incorporating into different populations and contexts. Moreover, to do so in a brief intervention of only three sessions, which in itself shows changes in the participants regardless of which variant of contextual therapy is used. Finally, the demand for interventions in the adolescent population with psychological problems is increasing. Thus, introducing a rigorous methodology based on functional contextualism that is attractive to students in a population sensitive to change, is an option that could have a beneficial impact on adolescents and improve their educational and personal future.

\section{References}

A-Tjak, J. G., Davis, M. L., Morina, N., Powers, M. B., Smits, J. A., \& Emmelkamp, P. M. (2015). A meta-analysis of the efficacy of acceptance and commitment therapy for clinically relevant mental and physical health problems. Psychotherapy and Psychosomatics, 84, 30- 36. doi: 10.1159/000365764

Andrews, B., \& Wilding, J. M. (2004). The relation of depression and anxiety to life-stress and achievement in students. British Journal of Psychology, 95, 509-521. doi: 10.1348/0007126042369802

Atienza, F. L., Pons, D., Balaguer, I., \& García-Merita, M. (2000). Propiedades psicométricas de la escala de satisfacción con la vida en adolescentes [Psychometric properties of the Life Satisfaction Scale in adolescents]. Psicothema, 12(2), 314-319.

Barkham, M., \& Shapiro, D. A. (1990). Brief psychotherapeutic interventions for job-related distress: A pilot study of prescriptive and exploratory therapy. Counselling Psychology Reviews, 3, 133-147. doi: 10.1080/09515079008254242

Blanco, C., Okuda, M., Wright, C., Hasin, D. S., Grant, B. F., Liu, S. M., \& Olfson, M. (2008). Mental health of college students and their non-college-attending peers: Results from the National Epidemiologic Study on Alcohol and Related Conditions. Archives of General Psychiatry, 65(12), 1429-1437. doi:_10.1001/archpsyc.65.12.1429

Bond, F. W., Hayes, S. C., Baer, R. A., Carpenter, K. M., Orcutt, H. K., Waltz, T., \& Zettle, R. D. (2011). Preliminary psychometric properties of the Acceptance and Action Questionnaire-II: A revised measure of psychological inflexibility and experiential avoidance. Behavior Therapy, 42(4), 676-688. doi: 10.1016/j.beth.2011.03.007

Brown, K. W., \& Ryan, R. M. (2003). The benefits of being present: mindfulness and its role in psychological wellbeing. Journal of Personality and Social Psychology, 84, 822-848.

Callaghan, G. M., Gregg, J. A., Marx, B. P., Kohlenberg, B. S., \& Gifford, E. (2004). FACT: The utility of an integration of functional analytic psychotherapy and acceptance and commitment therapy to alleviate human suffering. Psychotherapy: Theory, Research, Practice, Training, 41, 195-207. doi: 10.1037/0033-3204.41.3.195

Cattivelli, R., Musetti, A., \& Perini, S. (2014). L'approccio ACT-FAP nella promozione delle abilità sociali in adolescenti e preadolescenti con difficoltà emotive [The ACT-FAP training of social skills in adolescents and preteens with emotional difficulties]. Psicologia dell'Educazione, 8, 97-112.

Cohen, J. (1992). A power primer. Psychological Bulletin, 112(1), 155-159. doi: 10.1037/0033-2909.112.1.155

Danitz, S. B., Suvak, M. K., \& Orsillo, S. M. (2016). The mindful way through the semester: Evaluating the impact of integrating an acceptance-based behavioral program into a 
first-year experience course for undergraduates. Behavior Therapy, 47(4), 487-499. doi: 10.1016/j.beth.2016.03.002

Diener, E., Emmons, R., Larson, R. J., \& Griffin, S. (1985). The Satisfaction with Life Scale. Journal of Personality Assessment, 49, 71-75. doi: 10.1207/s15327752jpa4901_13

Duffy, M. E., Twenge, J. M., \& Joiner, T. E. (2019). Trends in mood and anxiety symptoms and suicide-related outcomes among US undergraduates, 2007-2018: Evidence from two national surveys. Journal of Adolescent Health, 65(5), 590-598. doi: 10.1016/j.jad.2020.12.183

Flaxman, P., Bond, F., \& Livheim, F. (2013). The mindful and effective employee: an acceptance \& commitment therapy training manual for improving well-being and performance. Oakland, CA: New Harbinger Publications.

García-Pérez, L., \& Valdivia-Salas, S. (2018). Intervención en el trastorno de ansiedad social a través de la terapia de aceptación y compromiso: Una revisión sistemática [Intervention in the social anxiety disorder through acceptance and commitment therapy: A systematic review]. Behavioral Psychology/Psicología Conductual, 26(2), 379-392.

García, J. F., \& Musitu, G. (1999). AF5. Autoconcepto forma 5 [AF5 Self-Concept Form 5]. Madrid: TEA.

Gillard, D., Flaxman, P., \& Hooper, N. (2018). Acceptance and commitment therapy: Applications for educational psychologists within schools. Educational Psychology in Practice, 1-10. doi: 10.1080/02667363.2018.1446911

Glover, N. G., Sylvers, P. D., Shearer, E. M., Kane, M. C., Clasen, P. C., Epler, A. J., \& Jakupcak, M. (2016). The efficacy of focused acceptance and commitment therapy in VA primary care. Psychological Services, 13, 156. doi: 10.1037/ser0000062

Goldberg, D. P. (1996). Cuestionario de salud general de Goldberg. Barcelona: Masson.

Grégoire, S., Lachance, L., Bouffard, T., Hontoy, L. M., \& De Mondehare, L. (2016). L'efficacité de l'approche d'acceptation et d'engagement en regard de la santé psychologique et de l'engagement scolaire des étudiants universitaires [The effectiveness of the approach of acceptance and commitment with regard to the psychological health and academic engagement of university students]. Canadian Journal of Behavioural Science/Revue Canadienne des Sciences du Comportement, 48(3), 222-231. doi: 10.1037/cbs0000040

Halliburton, A. E., \& Cooper, L. D. (2015). Applications and adaptations of acceptance and commitment therapy (ACT) for adolescents. Journal of Contextual Behavioral Science, 4(1), 1-11 doi: 10.1016/j.jcbs.2015.01.002

Hayes, S. C. (2019). Acceptance and commitment therapy: Towards a unified model of behavior change. World Psychiatry, 18(2), 226. doi: 10.1002/wps.20626

Hayes, S. C., Barnes-Holmes, D., \& Roche, B. (2001). Relational frame theory: A postSkinnerian account of human language and cognition. New York, NY: Kluwer Academic/ Plenum.

Hayes, S. C., Luoma, J. B., Bond, F. W., Masuda, A., \& Lillis, J. (2006). Acceptance and commitment therapy: Model, processes, and outcomes. Behaviour Research and Therapy, 44, 1-25. doi: 10.1016/j.brat.2005.06.006

Hayes, S. C., Strosahl, K. D., \& Wilson, K. G. (1999). Acceptance and commitment therapy: An experiential approach to behavior change. New York, NY: Guilford.

Kanter, J. W., Manbeck, K., Kuczynski, A. M., Maitland, D. M., Villas- Bôas, A., \& Reyes, M. (2017). A comprehensive review of research on functional analytic psychotherapy. Clinical Psychology Review, 58, 141-156. doi: 10.1016/j.cpr.2017.09.010

Keogh, E., Bond, F. W., \& Flaxman, P. E. (2006). Improving academic performance and mental health through a stress management intervention: Outcomes and mediators of change. Behaviour Research and Therapy, 44(3), 339-357. doi: 10.1016/j.brat.2005.03.002 
Kohlenberg, R. J., \& Tsai, M. (2021). FAP. Psicoterapia analítica funcional: creación de relaciones terapéuticas intensas y curativas [Functional analytic psychotherapy: Creating intense and curative therapeutic relationships]. Córdoba, España: Psara Ediciones. (Orig. 1991).

Kohlenberg, R. J., Hayes, S. C., \& Tsai, M. (1993). Radical behavioral psychotherapy: Two contemporary examples. Clinical Psychology Review, 13(6), 579-592. doi: 10.1016/0272-7358(93)90047-P

Kulakow, S. (2020). Academic self-concept and achievement motivation among adolescent students in different learning environments: Does competence-support matter? Learning and Motivation, 70, 101632. doi: 10.1016/j.Imot.2020.101632

Macías, J., \& Valero, L. (2021a). Fundamentos y aplicaciones clínicas de FACT: Una intervención para abordar el sufrimiento humano a través de las terapias contextuales [Fundamentals and clinical applications of FACT: An intervention to address human suffering through contextual therapies]. Madrid: Pirámide.

Macías, J., \& Valero, L. (2021b). La utilidad de la integración de la psicoterapia analíticafuncional y la terapia de aceptación y compromiso (FACT) para mejorar el estrés laboral: Dos estudios de caso [The utility of an integration of functional analytic psychotherapy and acceptance and commitment therapy (FACT) to enhance work stress: Two cases study]. Análisis y Modificación de Conducta, 47(175), 133-146. doi: 10.33776/amc.v47i175.4803

Macías, J., Valero-Aguayo, L., Bond, F. W., \& Blanca, M. J. (2019). The efficacy of functionalanalytic psychotherapy and acceptance and commitment therapy (FACT) for public employees. Psicothema, 31(1), 24-29. doi: 10.7334/psicothema2018.202

Megivern, D., Pellerito, S. y Mowbray, C. (2003). Barriers to higher education for individuals with psychiatric disabilities. Psychiatric Rehabilitation Journal, 26(3), 217.

Muñoz-Martínez, A. M. y Follette, W. C. (2019). When love is not enough: The case of therapeutic love as a middle-level term in functional analytic psychotherapy. Behavior Analysis: Research and Practice, 19(1), 103-113. doi: doi.org/10.1037/bar0000141

Páez-Blarrina, M., \& Luciano, C. (2012). La integración de ACT y FAP en el trabajo con patrones rígidos de comportamiento [The integration of ACT and FAP in working with rigid patterns of behaviour]. In M. Páez-Blarrina y O. Gutiérrez-Martínez (Eds.), Múltiples aplicaciones de la terapia de aceptación y compromiso [Multiple Applications of the Acceptance and Commitment Therapy] (pp. 47-72). Madrid, Spain: Pirámide.

Powers, M.B., Zum Vorde Sive Vording, M. B., \& Emmelkamp, M. P. (2009). Acceptance and commitment therapy: A meta-analytic review. Psychotherapy and Psychosomatics, 78, 73-80. doi: 10.1159/000190790

Ruiz, F. J., Langer, A. I., Luciano, C., Cangas, A. J., \& Beltrán, I. (2013). Measuring experiential avoidance and psychological inflexibility: The Spanish translation of the acceptance and action questionnaire-II. Psicothema, 25, 123-129. doi: 10.7334/psicothema2011.239

Sánchez-Lopez, M. P., \& Dresch, V. (2008). The 12-Item general health questionnaire (GHQ12): Reliability, external validity, and factor structure in the Spanish population. Psicothema, 20, 839-843. doi: 10.13140/RG.2.1.3240.4644

Soler-Ribaudi, J., Tejedor, R., Feliu-Soler, A., Segovia, P., Carlos, J., Cebolla i Martí, Soriano, J., Álvarez, E., \& Pérez, V. (2012). Propiedades psicométricas de la versión española de la escala Mindful Attention Awareness Scale (MAAS) [Psychometric properties of the Spanish version of the Mindful Attention Awareness Scale]. Actas Españolas de Psiquiatría, 40(1), 19-26.

Stabbe, O. K., Rolffs, L. C., \& Rogge, R. D. (2019). Flexibility and/or inflexibility embracing life: Identifying fundamental approaches to life with latent profile analysis on the dimensions of the Hexaflex model. Journal of Contextual Behavioral Science, 12, 106-118. doi: 10.1016/j.jcbs.2019.03.003 
Strosahl, K., Robinson, P., \& Gustavsson, T. (2012). Brief interventions for radical change: Principles \& practice of focused acceptance \& commitment therapy. Oakland, CA: New Harbinger.

Swain, J., Hancock, K., Dixon, A., \& Bowman, J. (2015). Acceptance and commitment therapy for children: A systematic review of intervention studies. Journal of Contextual Behavioral Science, 4(2), 73-85. doi: 10.1016/j.jcbs.2015.02.001

Takahashi, F., Ishizu, K., Matsubara, K., Ohtsuki, T., \& Shimoda, Y. (2020). Acceptance and commitment therapy as a school-based group intervention for adolescents: An openlabel trial. Journal of Contextual Behavioral Science. doi: 10.2975/26.2003.217.231 10.1016/j.jcbs.2020.03.001

Törneke, N., Luciano, C., Barnes-Holmes, Y., \& Bond, F. W. (2015). RFT for clinical practice: Three core strategies in understanding and treating human suffering. The Wiley Handbook of Contextual Behavioral Science, 254-272.

Tsai, M., Kohlenberg, R. J., Kanter, J. W., Kohlenberg, B., Follette, W. C., \& Callaghan, G. M. (2009). A guide to functional analytic psychotherapy: awareness, courage, love, and behaviorism. New York, NY: Springer.

Wang, D., Hagger, M. S., \& Chatzisarantis, N. L. (2020). Ironic effects of thought suppression: A meta-analysis. Perspectives on Psychological Science, 15(3), 778-793. doi: $10.1177 / 1745691619898795$

Wilson, K. G., \& Luciano, M. C. (2002). Terapia de aceptación y compromiso (ACT). Un tratamiento conductual orientado a los valores [Acceptance and commitment therapy $(\mathrm{ACT})$. A value-oriented behavioural treatment]. Madrid, Spain: Pirámide. 


\section{Appendix 1}

\section{The activities and processes carried out in the programme based on acceptance and} commitment therapy (ACT)

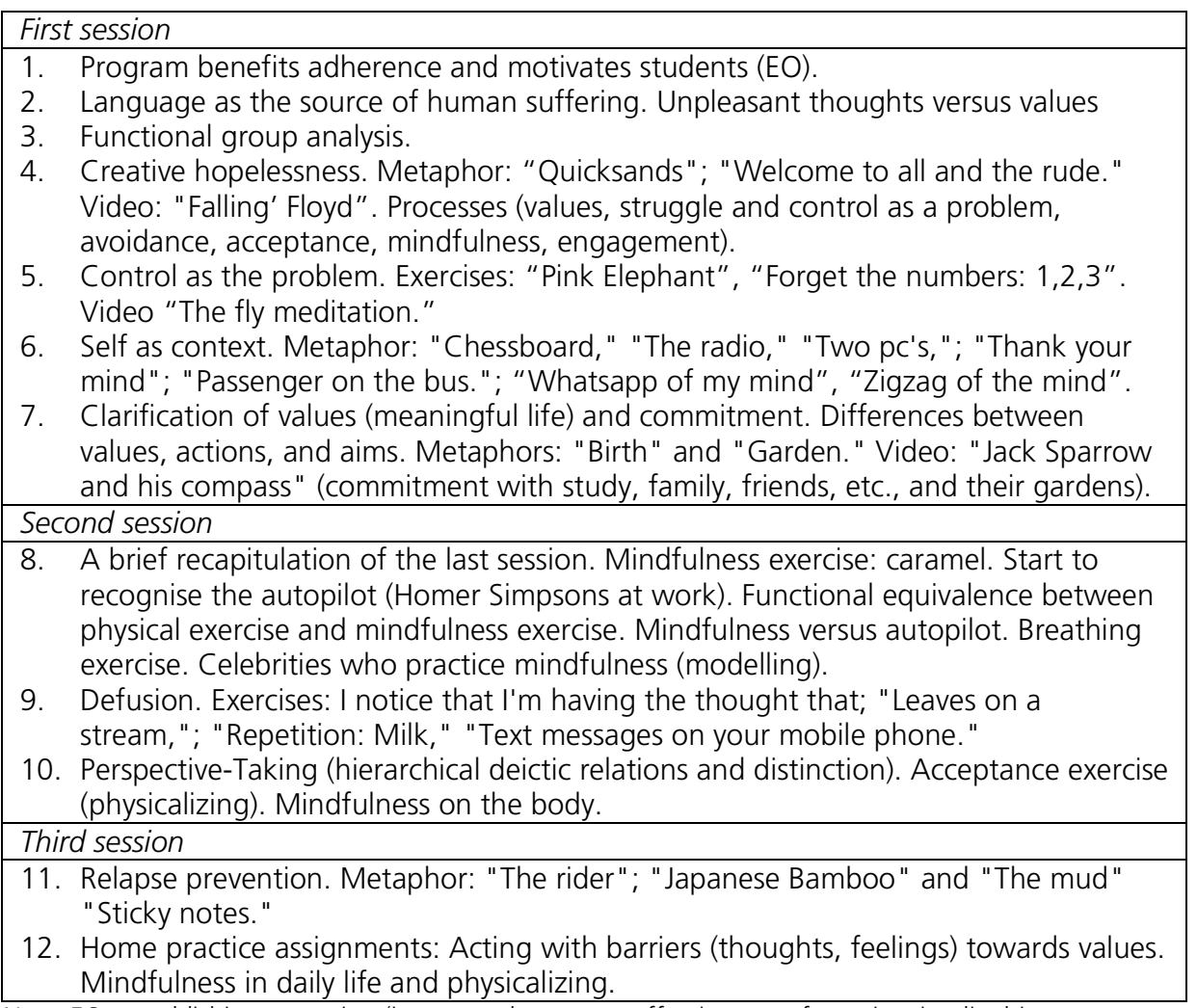

Note: $\mathrm{EO}=$ establishing operation (increases the current effectiveness of certain stimuli, objects, or events as reinforcement). 


\title{
Appendix 2
}

\section{The activities and processes carried out in the programme based on functional acceptance and commitment therapy (FACT)}

\author{
First session \\ 1. Program benefits adherence and motivates students (EO). Building empathy, \\ awareness, courage, and love (ACL model of FAP). Self-disclosures, shaping, and \\ modeling towards target behaviors. \\ 2. Emphasis on the therapeutic alliance, emotional validation, and positive \\ reinforcement. The confidential and safe atmosphere within the group.
}

3. Language as the source of human suffering. Unpleasant thoughts versus values

4. Functional group analysis.

5. Evoke clinically relevant behaviours type 1, and differentially reinforce clinically relevant behaviours type 2 with multiple examples.

6. Creative hopelessness. Metaphor: "Quicksands"; "Welcome to all and the rude." Video: "Falling' Floyd". Processes (values, struggle and control as a problem, avoidance, acceptance, mindfulness, engagement).

7. Control as the problem. Exercises: "Pink Elephant", "Forget the numbers: 1,2,3". Video "The fly meditation".

8. Self as context. Metaphor: "Chessboard," "The radio," "Two pc's, "; "Thank your mind"; "Passenger on the bus."; "Whatsapp of my mind", "Zigzag of the mind".

9. Clarification of values (meaningful life) and commitment. Differences between values, actions, and aims. Metaphors: "Birth" and "Garden." Video: "Jack Sparrow and his compass" (commitment with study, family, friends, etc., and their gardens).

Second session

10. A brief recapitulation of the last session. Mindfulness exercise: caramel. Start to recognise the autopilot (Homer Simpsons at work). Functional equivalence between physical exercise and mindfulness exercise. Mindfulness versus autopilot. Breathing exercise. Celebrities who practice mindfulness (modelling).

11. Defusion. Exercises: I notice that I'm having the thought that; "Leaves on a stream, "; "Repetition: Milk," "Text messages on your mobile phone."

12. Perspective-Taking (hierarchical deictic relations and distinction). Acceptance exercise (physicalizing). Mindfulness on the body.

Third session

13. Relapse prevention. Metaphor: "The rider"; "Japanese Bamboo" and "The mud" "Sticky notes."

14. Home practice assignments seeking functional generalization and functional interpretation (clinically relevant behaviours type 3). Acting with barriers (thoughts, feelings) towards values. Mindfulness in daily life and physicalizing.

Note: $\mathrm{EO}=$ establishing operation (increases the current effectiveness of certain stimuli, objects, or events as reinforcement). 